\title{
Perpetrating Cyber Dating Abuse: A Brief Report on the Role of Aggression, Romantic Jealousy and Gender
}

\author{
Heather Deans ${ }^{1}$ \& Manpal Singh Bhogal ${ }^{1,2}$
}

\begin{abstract}
There is increasing evidence that the use of elec-tronic communication technology (ECT) is being integrated into romantic relationships, which can be used as a medium to control a romantic partner. Most research focuses on the vic-tims of cyber dating abuse, however, we focused on the factors that predict perpetration of cyber dating abuse. We explored whether aggression (verbal aggression, physical aggression, anger and hostility), romantic jealousy (emotional, cognitive and behavioral jealousy), and gender predicted perpetration of cyber dating abuse $(n=189)$. We found that hostility, behav-ioral jealousy and gender significantly predicted perpetration of cyber dating abuse. The findings of this study contribute to our understanding of the psychological factors that drive cyber dating abuse in romantic relationships.
\end{abstract}

\section{Introduction}

Cyber dating abuse refers to physical, verbal and psychological abuse perpetrated towards a romantic partner (Jackson 2007).

* Manpal Singh Bhogal

ab6430@coventry.ac.uk

1 School of Psychological, Social and Behavioural Sciences, Coventry University, Priory Street, Coventry CV1 5FB, UK

2 Psychology Department, School of Life Sciences and Education, Staffordshire University, Stoke-on-Trent ST4 2DE, UK
Cyber abuse in dating relationships can involve threatening, harassing, impersonating, humiliating, or verbally abusing a dating partner using technology, such as mobile phones, social networking sites, or electronic mail (Wolford-Clevenger et al. 2016). Electronic communication technology (ECT) is a common method of communicating with partners, with some people using it as a means of controlling a romantic partner (Postmus 2013). Through ECT, cyber dating abuse has now become easier to perpetrate, allowing couples to stay connected through instant messaging and social net-working sites (Liébana-Cabanillas et al. 2014; Taylor et al. 2013). Although research has been conducted ex-ploring cyber dating abuse from the perspective of the victim, there is a lack of research focusing on the perpe-tration of cyber dating abuse (Stonard et al. 2014).

The use of technology within romantic relationships has led to an increase in relational conflict, heightened jealousy and increased partner monitoring (Rueda et al. 2014). Arguably, this may be because advancements in technology have redefined the boundaries of romantic relationships in ways that provide increased opportunity for abuse to occur (Draucker and Martsolf 2010). Technological advancements have provided new opportunities for perpetrators of dating abuse to be able to degrade, humiliate, and victimize their partner, even in the absence of their partner's physical presence (Zweig et al. 2013), causing psychological and emotional harm. The use of ECT in romantic relationships can cause unhealthy, controlling and intimidating behaviors (Stonard et al. 2015). Cyber dating abuse can be detrimental, leading to depression, anxiety disorders and isolation in victims (Teten et al. 2009). As a result of the detrimental effects experienced by victims of cyber dating use, it is important to explore the factors that predict the perpetration of cyber dating abuse.

Previous research has examined several factors that are associated with cyber dating abuse, such as gender, 
aggressiveness (Wolford-Clevenger et al. 2016; Borrajo et al. 2015b; Zweig et al. 2013), cyberbullying (Yahner et al. 2014), cyberstalking, jealousy (Strawhun et al. 2013), psychological and physical violence, and the prevalence and frequency of cyber dating abuse (Borrajo et al. 2015a, b). As a result, we conducted a study exploring whether psychological and behavioral determinants predict perpetration of cyber dating abuse, which are discussed next.

\section{Aggression and Cyber Dating Abuse}

Anger is defined as involving 'physiological arousal and preparation for aggression', whereas hostility is defined as 'feelings of ill will and injustice' (Buss and Perry 1992, p. 457). Verbal aggression is defined as behavior that causes verbal or mental distress, with an aim to control, intimidate, or psychologically harm another person. Verbal aggression can occur in online contexts, making it distinct to physical aggression, which typically occurs in an offline context (Follingstad 2007). Physical and verbal aggression involve the motor component of behavior, with the aim of 'hurting or harming others' (Buss and Perry 1992, p. 457). ECT may reduce the threat of physical aggression (Melander 2010), which may be due to individuals using ECT to direct cyber dating abuse towards their partners in an indirect manner, which is not always possible with physical aggression. Furthermore, Borrajo et al. (2015b) found that offline aggression (face-toface aggression) was not associated with cyber dating abuse, whereas online aggression (verbal aggres-sion, hostility) was associated with cyber dating abuse.

Draucker and Martsolf (2010) found that partners use ECT as a tool to argue, monitor, or show aggression toward a partner. In support, Strawhun et al. (2013) found that physical aggression was a significant predictor of the perpetration of cyberstalking. In sum, aggression appears to play a part in predicting psychological abuse in relationships. From a psychological perspective, anger and hostility may drive the perpetrator to engage in cyber dating abuse (Ali and Naylor 2013), but further empirical investigation is required.

\section{Romantic Jealousy and Cyber Dating Abuse}

Behavioral jealousy is defined as behavioral reactions which are driven by jealousy, with an aim to monitor, control, and engage in the surveillance of a romantic partner (Elphinston et al. 2011). Emotional jealousy is defined as emotional reactions (such as anger, sadness) to threats from rivals to a romantic relationship, whereas cognitive jealousy refers to having thoughts about a partner engaging in infidelity (Buunk 1997). It is important to note that cognitive jealousy and behavioral jealousy have the potential to be pathological (Pfeiffer and Wong 1989), and could therefore lead to the perpetration of abuse in a romantic relationship.
Jealousy is an important predictor of relationship conflict (Christofides et al. 2009), as feelings of jealousy lead to hostile and abusive behavior towards romantic partners (Shackelford 2001). In support, jealousy is negatively related to relationship quality (Barelds and Dijkstra 2006). Recent research suggest that the use of social networking sites increase the risk of a partner developing feelings of jealousy towards a part-ner. This may be related to the information that their part-ner may share, such as revealing personal information and sharing personal pictures, thus increasing the likelihood of jealous reactions and thoughts that a partner may be en-gaging in infidelity (Miller et al. 2014).

Surveillance and harassment can both occur within the perpetration of cyber dating abuse, which may be driven by behavioral jealousy, suggesting behavioral jealousy may predict the perpetration of cyber dating abuse. On the other hand, those who engage in surveillance do care about maintaining their relationship, particularly in seeking reassurance that the relationship is not under threat of dissolution (Elphinston et al. 2013). Similarly, Carson and Cupach (2000) suggest that engaging in surveillance behaviors may lead to relationship security, indicating that behavioral jealousy is not always negative or abusive. However, Dye and Davis (2003) argue that jealousy and obsessiveness often lead to monitoring and surveillance of one's partner which further supports the need to explore the predictors of cyber dating abuse in more detail.

Lucero et al. (2014) found that jealousy has to be extreme before it is viewed as abusive, as jealousy can be viewed as normal and a positive sign of a partner's love, even when jealousy leads to abusive behaviors. According to evolutionary theory, jealousy is argued to be a mate retention tactic (Buss and Shackelford 1997). Jealousy in some cases is described as being healthy and positive for a relationship, and can remind an individual of the importance of their partner and the relationship (Elphinston et al. 2013). However, jealousy is considered morbid when it becomes possessive and extreme (Marazziti et al. 2003). Jealousy can become unhealthy in a relationship when an individual negatively affects their part-ner, such as interfering with their daily activities (such as monitoring email accounts and social media accounts, Borrajo et al. 2015a, b) and other relationships. There are also implications for relationship quality, as jealousy can result in the misinterpretation of cues causing increased feelings of jealousy, leading to higher rates of cyber dating abuse (Christofides et al. 2009). As well as exploring jealousy and aggression, it is also crucial to consider the effect of gender in relation to the perpetration of cyber dating abuse.

\section{Gender and Cyber Dating Abuse}

The literature exploring the effect of gender on cyber dating abuse has produced inconsistent findings (Borrajo et al. $2015 \mathrm{a}, \mathrm{b})$. This may be because men and women engage in 
the perpetration of cyber dating abuse differently. For example, some claim that young men engage in more direct acts of aggression (Perry and Pauletti 2011), whereas others suggest that women engage in more indirect acts of aggression (Hyde 2005), particularly towards other women (Keys and Bhogal 2016) and their romantic partners (Hokoda et al. 2012).

\section{The Present Study}

The aim of our study was to expand upon the limited literature available, by focusing on whether aggression, jealousy, and gender predicted perpetration of cyber dating abuse. We hypothesized that aggression, jealousy, and gender would significantly predict the perpetration of cyber dating abuse. This study focused primarily on perpetration, as opposed to being a victim of cyber dating abuse as this area is under-researched.

\section{Method}

\section{Participants and Design}

One hundred, eighty-nine heterosexual participants took part from Coventry University (152 females, 37 males, mean age = 19.2 years, SD = 1.94). Participants were recruited via opportunity sampling through the department's research participation scheme. We chose a student sample, as the use of ECT such as social networking sites and instant messaging are more popular and more commonly used by young adults compared to older adults (Correa et al. 2010). In addition, those between 20 and 24 years of age experience the highest rates of intimate partner violence (Marganski and Fauth 2013). A prerequisite was that participants should currently be in a romantic relationship.

A multiple regression model was adopted in which there were eight predictor variables; verbal aggression, physical ag-gression, anger, hostility, cognitive jealousy, emotional jeal-ousy, behavioral jealousy, and gender. The outcome variable was the perpetration of cyber dating abuse.

\section{Materials and Procedure}

This study was approved by the research ethics committee at Coventry University. Data were collected online due to the sensitive nature of the topic. Participants completed a demo-graphic questionnaire, followed by three validated question-naires to measure each variable of interest;

Aggression - The Buss-Perry Aggression Questionnaire (1992) measures aggression through four sub-categories: physical aggression (nine items), verbal aggression (five items), anger (eight items) and hostility (eight items). Participants responded on a seven-point Likert scale ranging from extremely uncharacteristic of me (one) to extremely characteristic of me (seven). Cronbach alpha for this study was calculated for each subscale, physical aggression $(\alpha=$ $.85)$, verbal aggression $(\alpha=.77)$, anger $(\alpha=.81)$, and hostility $(\alpha=.83)$.

Romantic jealousy - The Multidimensional Jealousy Scale (Pfeiffer and Wong 1989) measures romantic jealousy through three dimensions: cognitive jealousy, emotional jealousy, and behavioral jealousy. The scale includes eight items for each dimension, with a total of 24 items. Participants responded on a seven-point Likert scale for all items, with cognitive jealousy ranging from all the time (one) to never (seven), emotional jealousy ranging from very pleased (one) to very upset (sev-en), and behavioral jealousy ranging from never (one) to all the time (seven). Cronbach alpha was calculated for each sub-scale, cognitive jealousy $(\alpha=.89)$, emotional jealousy $(\alpha=.79)$, and behavioral jealousy $(\alpha=.81)$.

Cyber dating abuse - The Cyber-Dating Abuse Questionnaire by Borrajo et al. (2015a, b) was used to mea-sure perpetration of cyber dating abuse. We used items that were relevant to our hypothesis. Participants responded on a six-point scale that measured how often a specific behavior occurred within their relationship, which ranged from never (one) to usually (six). Cronbach alpha value for this scale was $\alpha=.93$.

\section{Results}

Preliminary analyses were conducted to ensure no violation of the assumptions of normality, linearity, multicollinearity and homoscedasticity. Standard multiple regression was conducted to assess whether the predictor variables outlined previously predicted cyber dating abuse (perpetration). The total variance $\left(r^{2}\right)$ explained by the model was $28.3 \%, F(8,180)=$ 8.88, $\mathrm{p}<0.05$, Cohen's $\mathrm{f}^{2}=.39$. The model signifi-cantly predicted perpetration of cyber dating abuse. Table 1 provides descriptive statistics and beta values for all variables.

Behavioral jealousy was a significant, positive predictor of cyber dating abuse in that high levels of behavioral jealousy led to high levels of cyber dating abuse. Hostility was a significant, positive predictor of cyber dating abuse with high levels of hostility leading to high levels of cyber dating abuse. Furthermore, gender was a significant predictor of cyber dating abuse, with women reporting lower levels of perpetrating cyber dating abuse compared to men. The remaining predictor variables were non-significant predictors of cyber dating abuse.

\section{Discussion}

The aim of this study was to examine whether aggression, romantic jealousy, and gender significantly predicted 
Table 1 Descriptive statistics and regression coefficients

\begin{tabular}{llll}
\hline Predictor variables & Mean (SD) & $\beta$ & $p$ \\
\hline Physical aggression & $24.79(10.44)$ & -.13 & .10 \\
Verbal aggression & $20.00(5.84)$ & -.02 & .82 \\
Anger & $19.11(7.70)$ & .04 & .65 \\
Hostility & $27.67(10.05)$ & .25 & .01 \\
Cognitive jealousy & $22.30(10.51)$ & .11 & .13 \\
Emotional jealousy & $41.69(6.15)$ & -.13 & .06 \\
Behavioral jealousy & $16.42(6.63)$ & .32 & .00 \\
Gender $(1=$ male, $2=$ female $)$ & - & -.22 & .00 \\
Cyber dating abuse & $57.92(20.34)$ & - & - \\
\hline
\end{tabular}

perpetration of cyber dating abuse. Hostility, behavioral jealousy, and gender were the strongest predictors of perpetrating cyber dating abuse, partially supporting our hypothesis.

Behavioral jealousy was the strongest statistically significant predictor, which is consistent with previous research (e.g. Borrajo et al. 2015a, b; Sesar et al. 2014; Christofides et al. 2009). It is clear as to how behavioral jealousy contributed to perpetration of cyber dating abuse, as behavioral jealousy can drive one to engage in the monitoring and surveillance of a romantic partner (Dye and Davis 2003). However, previous research suggests that cognitive jealousy and behavioral jealousy commonly occur simultaneously (Attridge 2013; Elphinston et al. 2013), which is inconsistent with our findings. Although we may experience cognitive jealousy, this does not necessarily mean we engage in actual surveillance of a partner. One may possess jealous thoughts and feelings but choose to not express them, which could explain the reason as to why cognitive and emotional jealousy did not significantly predict perpetration of cyber dating abuse.

Gender was a significant predictor of cyber dating abuse, with women reporting less perpetration of cyber dating abuse than men, which is inconsistent with previous research where gender has been found to have no relationship with cyber dating abuse (see Borrajo et al. 2015a, b; Brown and Prinstein 2011). In fact, previous literature suggests women are more likely than men to perpetrate controlling behaviors online (Bennett et al. 2011; Burke et al. 2011). However, our finding related to gender should be taken with caution due to the unequal numbers of men and women in our sample.

Hostility was the only form of aggression that significantly contributed to the perpetration of cyber dating abuse, consistent with previous research, as hostility is associated with perpetration of abuse in romantic relationships (Capaldi and Crosby 1997; Lavoie et al. 2002). Vagi et al. (2013) reported that those who have a hostile relationship with their romantic partner are more likely to engage in cyber dating abuse. In support, Shackelford (2001) argues that higher levels of jealousy, hostility, and abusive behavior towards a romantic partner occur simultaneously. This is consistent with the findings of our study, as both behavioral jealousy and hostility contributed to the perpetration of cyber dating abuse towards a partner.

Although this study has provided some new insight into perpetration of cyber dating abuse, the study has some notable limitations. First, men may be less likely than women to participate in a study on dating abuse, as there is a greater stigma towards men when researching relational abuse (Foshee 1996). An equal number of men and women should be recruited, to enable a more generalized set of results. Second, the use of self-report data may have resulted in biased responses and social desirability (Coolican 2009). Some may not admit to perpetrating cyber abusive behaviors due to stigma and sensitivity of the topic. Third, in our sample, we did not include non-heterosexual couples. Fourth, we did explore whether ethnicity predicts cyber dating abuse. Last, we did not include a sample of a more diverse age range.

In sum, this study extends our understanding of the factors that contribute to the perpetration of cyber dating abuse, pro-viding support that those who report high levels of hostility and behavioral jealousy are more likely to abuse their roman-tic partner through ECT.

Acknowledgments We thank James E Bartlett for his valuable comments on an earlier draft of this manuscript.

Compliance with Ethical Standards

Conflicts of Interest There are no conflicts of interest.

Human Studies This research involved collecting data from human participants.

Informed Consent Informed consent was taken from all participants who took part in this study.

Ethical Approval All procedures performed in studies involving human participants were in accordance with the ethical standards of the institutional and/or national research committee and with the 1964 Helsinki declaration and its later amendments or comparable ethical standards.

\section{References}

Ali, P., \& Naylor, P. (2013). Intimate partner violence: A narrative review of the biological and psychological explanations for its causation. Aggression and Violent Behavior, 18(3), 373-382.

Attridge, M. (2013). Jealousy and relationship closeness: Exploring the good (reactive) and bad (suspicious) sides of romantic jealousy. SAGE open, 3, 1-16.

Barelds, D., \& Dijkstra, P. (2006). Reactive, anxious and possessive forms of jealousy and their relation to relationship quality among heterosexuals and homosexuals. Journal of Homosexuality, 51(3), 183-198. 
Bennett, D., Guran, E., Ramos, M., \& Margolin, G. (2011). College Students' electronic victimization in friendships and dating relationships: Anticipated distress and associations with risky behaviors. Violence and Victims, 26(4), 410-429.

Borrajo, E., Gámez-Guadix, M., Pereda, N., \& Calvete, E. (2015a). The development and validation of the cyber dating abuse questionnaire among young couples. Computers in Human Behavior, 48, 358- 365 .

Borrajo, E., Gámez-Guadix, M., \& Calvete, E. (2015b). Cyber dating abuse: Prevalence, context, and relationship with offline dating ag-gression. Psychological Reports, 116(2), 565-585.

Brown, B., \& Prinstein, M. (2011). Encyclopaedia of Adolescence. London: Elsevier Academic Press.

Burke, S., Wallen, M., Vail-Smith, K., \& Knox, D. (2011). Using tech-nology to control intimate partners: An exploratory study of college undergraduates. Computers in Human Behavior, 27(3), 1162-1167.

Buss, A., \& Perry, M. (1992). The Aggression Questionnaire. Journal of Personality and Social Psychology, 63(3), 452-459.

Buss, D. M., \& Shackelford, T. K. (1997). From vigilance to violence: Mate retention tactics in married couples. Journal of Personality and Social Psychology, 72, 346-361.

Buunk, B. (1997). Personality, birth order and attachment styles as related to various types of jealousy. Personality and Individual Differences, 23(6), 997-1006.

Capaldi, D., \& Crosby, L. (1997). Observed and reported psychological and physical aggression in young, at-risk couples. Social Development, 6(2), 184-206.

Carson, C., \& Cupach, W. (2000). Fuelling the flames of the green-eyed monster: The role of ruminative thought in reaction to romantic jealousy. Western Journal of Communication, 64(3), 308-329.

Christofides, E., Muise, A., \& Desmarais, S. (2009). Information disclo-sure and control on Facebook: Are they two sides of the same coin or two different processes? Cyber Psychology \& Behavior, 12(3), 341-345.

Coolican, H. (2009). Research methods and statistics in psychology (5th ed.). Great Britain: Hodder Education.

Correa, T., Hinsley, A., \& de Zúñiga, H. (2010). Who interacts on the web? The intersection of users' personality and social media use. Computers in Human Behavior, 26(2), 247-253.

Draucker, C., \& Martsolf, D. (2010). The role of electronic communication Technology in Adolescent Dating Violence. Journal of Child and Adolescent Psychiatric Nursing, 23(3), 133-142.

Dye, M., \& Davis, K. (2003). Stalking and psychological abuse: Common factors and relationship-specific characteristics. Violence and Victims, 18(2), 163-180.

Elphinston, R., Feeney, J., \& Noller, P. (2011). Measuring romantic jeal-ousy: Validation of the multidimensional jealousy scale in Australian samples. Australian Journal of Psychology, 63(4), $243-251$.

Elphinston, R., Feeney, J., Noller, P., Connor, J., \& Fitzgerald, J. (2013). Romantic jealousy and relationship satisfaction: The costs of rumination. Western Journal of Communication, 77(3), 293-304.

Follingstad, D. (2007). Rethinking current approaches to psychological abuse: Conceptual and methodological issues. Aggression and Violent Behavior, 12(4), 439-458.

Foshee, V. (1996). Gender differences in adolescent dating abuse preva-lence, types and injuries. Health Education Research, 11(3), 275- 286.

Hokoda, A., Martin Del Campo, M., \& Ulloa, E. (2012). Age and gender differences in teen relationship violence. Journal of Aggression, Maltreatment \& Trauma, 21(3), 351-364.

Hyde, J. (2005). The gender similarities hypothesis. American Psychologist, 60(6), 581-592.

Jackson, N. (2007). Encyclopaedia of domestic violence. New York: Routledge.
Keys, E., \& Bhogal, M. S. (2016). Mean Girls: Provocative clothing leads to intra-sexual competition between females. Current Psychology, Advance online publication. https://doi.org/10.1007/s12144-016-9536-X.

Lavoie, F., Hébert, M., Tremblay, R., Vitaro, F., Vézina, L., \& McDuff, P. (2002). History of family dysfunction and perpetration of dating violence by adolescent boys: A longitudinal study. Journal of Adolescent Health, 30(5), 375-383.

Liébana-Cabanillas, F., Sánchez-Fernández, J., \& Muñoz-Leiva, F. (2014). The moderating effect of experience in the adoption of mobile payment tools in virtual social networks: The M-payment acceptance model in virtual social networks (MPAM-VSN).

International Journal of Information Management, 34(2), 151-166.

Lucero, J., Weisz, A., Smith-Darden, J., \& Lucero, S. (2014). Exploring gender differences: Socially interactive technology use/abuse among dating teens. Affilia, 29(4), 478-491.

Marazziti, D., Di Nasso, E., Masala, I., Baroni, S., Abelli, M., Mengali, F., Mungai, F., \& Rucci, P. (2003). Normal and obsessional jealousy: A study of a population of young adults. European Psychiatry, 18(3), 106-111.

Marganski, A., \& Fauth, K. (2013). Socially interactive technology and contemporary dating: A cross-cultural exploration of deviant behaviors among young adults in the modern, evolving technological world. International Criminal Justice Review, 23(4), 357-377.

Melander, L. (2010). College Students' perceptions of intimate partner cyber harassment. Cyberpsychology, Behavior and Social Networking, 13(3), 263-268.

Miller, M., Denes, A., Diaz, B., \& Buck, R. (2014). Attachment style predicts jealous reactions to viewing touch between a romantic partner and close friend: Implications for internet social communication. Journal of Nonverbal Behavior, 38(4), 451-476.

Perry, D., \& Pauletti, R. (2011). Gender and Adolescent Development. Journal of Research on Adolescence, 21(1), 61-74.

Pfeiffer, S., \& Wong, P. (1989). Multidimensional jealousy. Journal of Social and Personal Relationships, 6(2), 181-196.

Postmus, J. (2013). Sexual violence and abuse. Santa Barbara: AbcClio. Rueda, H., Lindsay, M., \& Williams, L. (2014). BShe posted it on

Facebook $^{\wedge}$ : Mexican American adolescents' experiences with tech-nology and romantic relationship conflict. Journal of Adolescent Research, 30(4), 419-445.

Sesar, K., Dodaj, A., Simic, N., \& Barisic, M. (2014). Predictors of violent behaviors in young adults dating relationships. Psychology and Behavioral Sciences, 3(6), 233-242.

Shackelford, T. (2001). Self-Esteem in Marriage. Personality and Individual Differences, 30(3), 371-390.

Stonard, K., Bowen, E., Lawrence, T., \& Price, S. (2014). The relevance of technology to the nature, prevalence and impact of adolescent dating violence and abuse: A research synthesis. Aggression and Violent Behavior, 19(4), 390-417.

Stonard, K., Bowen, E., Walker, K., \& Price, S. (2015). BThey'll always find a way to get to $\mathrm{you}^{\wedge}$ : Technology use in adolescent romantic relationships and its role in dating violence and abuse. Journal of Interpersonal Violence, 32(14), 2083-2117.

Strawhun, J., Adams, N., \& Huss, M. (2013). The assessment of cyberstalking: An expanded examination including social network-ing, attachment, jealousy, and anger in relation to violence and abuse. Violence and Victims, 28(4), 715-730.

Taylor, A., Rappleyea, D., Fang, X., \& Cannon, D. (2013). Emerging adults' perceptions of acceptable behaviors prior to forming a com-mitted, dating relationship. Journal of Adult Development, 20(4), 173-184.

Teten, A., Ball, B., Valle, L., Noonan, R., \& Rosenbluth, B. (2009). Considerations for the definition, measurement, consequences, and prevention of dating violence victimization among adolescent girls. Journal of Women's Health, 18(7), 923-927. 